\title{
Formulation Development and Characterization of Levosalbutamol Sulphate Oral Thin Film using Propylene glycol as a Plasticizer
}

\author{
Md. Masud Morshed ${ }^{1}$, Jewel Mallick ${ }^{1}$, Fahamida Islam², Md. Kamrul Islam², \\ Md. Didaruzzaman Sohel ${ }^{2}$ and Md. Hassan Kawsar ${ }^{2}$ \\ ${ }^{1}$ Department of Pharmacy, BGC Trust University Bangladesh, Chittagong- 4381, Bangladesh \\ ${ }^{2}$ Department of Pharmacy, State University of Bangladesh, Dhanmondi, Dhaka- 1205, Bangladesh
}

Received: December 06, 2016; Accepted: December 29, 2016; Published (Web): March 19, 2017

\begin{abstract}
The present study was concerned with the preparation and evaluation of oral thin films of levosalbutamol sulphate (LS) is to avoid presystemic elimination by gastrointestinal degradation and first pass hepatic metabolism. The films were prepared using four different water soluble polymers in various proportions and combinations using propylene glycol as plasticizers. Total five formulations were developed and evaluated for the various physicochemical characteristics namely mass uniformity, thickness, folding endurance, density, surface $\mathrm{pH}$, swelling index, disintegration time, content uniformity, in vitro release profile, percent moisture absorption and loss and ex vivo mucoadhesion time. Data of every parameter were taken in triplicate. Results of film thickness, mass, density and swelling index of medicated films of LS were found with relatively low standard deviation along with high folding endurance $(>300)$. The surface $\mathrm{pH}$ of all films approached to the salivary fluid $\mathrm{pH}$ range (6.1 7.0). Disintegration time and content uniformity complied with standard for all formulations. Among the total five formulations, F-2 and F-5 followed first order release and F-1 and F-4 followed Higuchi release and F-5 followed zero order and hixon-crowell release. The residence time for mucoadhesion of the tested films ranged between 1 to 5 minutes. Percent moisture absorption and loss study revealed the excellent stability of the films in dried conditions and relatively low standard deviation indicated the stability also in humid conditions.
\end{abstract}

Key words: Oral thin film (OTF), Levosalbutamol sulphate (LS), Folding endurance, Propylene glycol (PG), Percent moisture absorption (PMA), Percent moisture loss (PML).

\section{Introduction}

The oral route for systemic delivery has been the preferred route of administration for many active pharmaceutical ingredients (API) and most acceptable from patient compliance aspects. When administered by the oral route, however, many API have been reportedly subjected to extensive presystemic elimination by gastrointestinal degradation and/or hepatic metabolism. Results of low systemic bioavailability, short duration of therapeutic activity, and/or formation of toxic and inactive metabolite have been often reported. Since the early 1980s, the concept of oral thin films has gained considerable interest in pharmaceutical technology. These thin films contain active pharmaceutical ingredient embedded in the matrix of film forming polymers in the presence of other excipients. The advantages of convenience of dosing and portability of oral thin films have led to wider acceptability of this dosage form by pediatric as well as geriatric population equally (Gavaskar et al., 2010).

The need for the fast dissolving oral thin films has been felt because of the variety of reasons (Bandari et al., 2008). Fast dissolving oral thin films represent the category of dosage forms that offers high patient compliance especially for the patients having difficulty in swallowing or chewing (Dixit et al., 2009; Suresh et al., 2003; Biradar et al., 2006). Oral administration of a drug can be made without the use of water and hence it can be taken anywhere anytime. This dosage form is a very good substitute for the liquid dosage forms and hence is suitable for pediatric and geriatric patients. Moreover, oral thin films are also devoid of friability problems associated with oro dispersible tablets (Alpesh et al., 2010). 
Levosalbutamol (INN) or levalbuterol (USAN), is the chirally pure R-enantiomer is a short-acting, selective $\beta_{2}$-adrenergic receptor agonist used in the treatment of asthma and COPD. It is 29 times more selective for $\beta_{2}$ receptors than $\beta_{1}$ receptors giving it higher specificity for pulmonary $\beta$ receptors versus $\beta_{1^{-}}$ adrenergic receptors located in the heart. Salbutamol is formulated as a racemic mixture of the $\mathrm{R}$ - and $\mathrm{S}$ isomers (Figure 1). The $\mathrm{R}$-isomer has 150 times greater affinity for the $\beta_{2}$-receptor than the S-isomer and the Sisomer has been associated with toxicity. This led to the development of Levosalbutamol, the single R-isomer of salbutamol (Schreck et al., 2005).

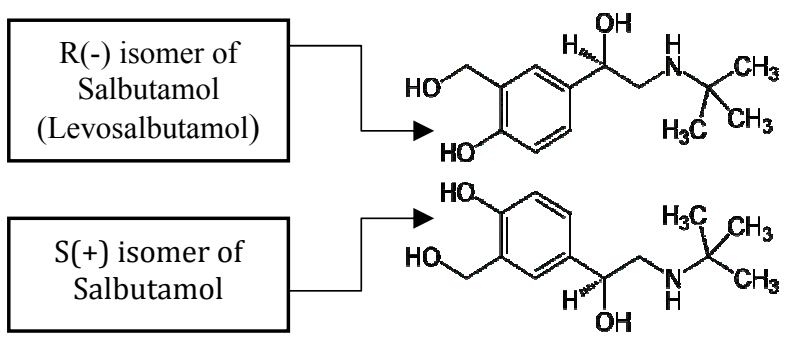

Figure 1. Structural formula of Salbutamol enantiomers.

The therapeutically inactive (S)-enantiomer in racemic salbutamol may be associated with increased airway hyper reactivity in patients with asthma. A large clinical study demonstrated that inhaled Levosalbutamol, $0.625 \mathrm{mg}$ or $1.25 \mathrm{mg} 3$ times daily, provided effective relief from the symptoms of asthma. Levosalbutamol $0.625 \mathrm{mg}$ was at least as effective as racemic salbutamol $2.5 \mathrm{mg}$. Levosalbutamol was well tolerated in clinical trials and the risk/benefit ratio was reported to be superior to that of racemic salbutamol
(Khairwa et al., 2013). So, the purpose of this research work was to develop formulations of therapeutically effective LS in form of oral thin films as a better substitute as compared with other oral dosage forms.

\section{Materials and Methods}

Levosalbutamol sulfate $I N N$ was obtained as a gift from Beximco Pharmaceuticals Ltd, Bangladesh. The polymers hydroxypropyl methyl cellulose (HPMCK4M), carbopol 934p (Cp), polyvinyl pyrolidone (PVP K30) were procured from Les Laboratories Servier, France. Propylene glycol (PG) was purchased from Merck, Germany. All other chemicals and reagents were of analytical grade. Fresh pig buccal mucosa was obtained from a local slaughterhouse and was used within 2 hours of slaughter.

Formulation of films: The oral thin films of LS were prepared by the solvent casting technique using water as a solvent. Different polymeric combinations were tried out (HPMC/SCMC, $\mathrm{HPMC} / \mathrm{CP}$, HPMC/PVP, HPMC/CP/PVP, HPMC-CP-SCMC and subjected with various polymeric combinations. Aqueous polymer solutions of different concentrations were mixed in different ratios as mentioned in the Table 1.

An aqueous solution of $2 \% \mathrm{~m} / \mathrm{V}$ HPMC K4M \& PVP K30 and $1 \% \mathrm{~m} / \mathrm{V}$ of $\mathrm{CP} 934 \mathrm{P} \& \mathrm{SCMC}$ were prepared by dissolving in a fixed quantity of distilled water. Methanol (absolute) about $1 \mathrm{~mL}$ was used to dissolve the drug (Poddar et al., 2009; Prasanth et al., 2011).

Table 1. Design layout and composition of oral thin film formulations of LS.

\begin{tabular}{ccccccc}
\hline $\begin{array}{c}\text { Formulation } \\
\text { code }\end{array}$ & $\begin{array}{c}\mathrm{LS} \\
(\mathrm{mg})\end{array}$ & $\begin{array}{c}\text { PG } \\
(\mathrm{ml})\end{array}$ & $\begin{array}{c}\text { HPMC- K4M } \\
(2 \% \mathrm{~m} / \mathrm{V} \mathrm{ml})\end{array}$ & $\begin{array}{c}\text { CP 934P } \\
(1 \% \mathrm{~m} / \mathrm{V} \mathrm{ml})\end{array}$ & $\begin{array}{c}\text { SCMC } \\
(1 \% \mathrm{~m} / \mathrm{V} \mathrm{ml})\end{array}$ & $\begin{array}{c}\text { PVP K30 } \\
(2 \% \mathrm{~m} / \mathrm{V} \mathrm{ml})\end{array}$ \\
\hline F-1 & 117.6 & 5 & 50 & - & 25 & - \\
F-2 & 117.6 & 5 & 50 & 25 & - & - \\
F-3 & 117.6 & 5 & 50 & - & - & 25 \\
F-4 & 117.6 & 5 & 40 & 20 & - & 15 \\
F-5 & 117.6 & 5 & 40 & 20 & 15 & - \\
\hline
\end{tabular}

To this polymeric solution, calculated amount of drug taking the dose of Levosalbutamol $1 \mathrm{mg}$ equivalent to $2.4 \mathrm{mg}$ LS for each film was gradually added and mixed thoroughly with PG and sodium saccharine as a sweetener to mask the bitter taste. The suspension was stirred for $30 \mathrm{~min}$ by propeller mixer to get a homogenous drug-polymer mixture. After proper mixing, the films were vacuum dried for 30 minutes at 
room temperature in vacuum desiccators to remove undesired bubbles. This drug-polymeric solution was then poured into a 14 x $14 \mathrm{~cm}^{2}$ specially fabricated square glass plate carefully to cover all the edges of square plate. Films were then allowed to dry at room temperature for 1 hour followed by dried for $18 \mathrm{hrs}$ at $60^{\circ} \mathrm{c}$ in a hot air oven (Daihan, Korea). Finally, after careful examination, the dried films were removed, checked for any imperfections or air bubbles and cut into $2 \times 2 \mathrm{~cm}^{2}$ diameter films using a stainless steel cutter. The samples were packed in High Density Polyethylene (HDPE) sheet, sealed and stored in desiccators at room temperature. The film samples were also stored for accelerated stability studies as per International Conference on Harmonization (ICH) guidelines.

\section{Evaluation of Films}

(i) Film thickness: Assessment of film thickness was done on 10 films and four regions thickness data for individual film should be required using micrometer screw gauge (Mitutoyo Corporation, Japan).

(ii) Mass uniformity: Mass uniformity of prepared films was tested in three randomly selected individual films from each batch using an electronic balance (Mettler Toledo, Japan).

(iii) Folding endurance: The folding endurance along with tensile strength of a film is related to the flexibility of a film and hence represents its physical stability during manufacturing, packing and use. It was measured manually by firmly folding a film repeatedly through the middle. The number of folds on the crease, required to produce crack in the film was noted as the value of folding endurance. (Shinde et al., 2009).

(iv) Surface $\mathrm{pH}$ : Agar plate, prepared by dissolving $2 \%(\mathrm{~m} / \mathrm{V})$ agar in warmed isotonic phosphate buffer of $\mathrm{pH} 6.8$ under stirring and then pouring the solution in a petridish $(80 \mathrm{~mm})$ and cooling till gelling at room temperature. Films were left to swell for $2 \mathrm{~h}$ on the surface of these plates. The surface $\mathrm{pH}$ was measured by means of a $\mathrm{pH}$ paper (Lojak, Korea) placed on the surface of the swollen patch.

(v) Density: In order to ensure how much dense the prepared film, the following formula is used.

$$
\text { Density }=\frac{\text { Mass of the film }}{\text { Volume }}
$$

Here, Volume $=$ thickness of the film $\mathrm{x}$ total area of the film

(vi) In vitro disintegration time: Two simple methods were used using small amount of medium. In the first method, one drop of water was dropped from a $10 \mathrm{~mL}$ pipette onto the tightly clamped film. The time taken to make a hole through the film was measured as disintegration time (DT). In the second method $2 \mathrm{~mL}$ of water was taken in a petri plate and a film was placed on the surface of water and time taken for disintegration of the film was measured as DT. This test was done in triplicate as average value was taken as DT.

(vii) Drug content evaluation: The prepared film was allowed to dissolve in $10 \mathrm{~mL}$ of simulated saliva solution ( $\mathrm{pH}$ 6.2) for 2-3 hours under occasional shaking. The resultant solution was filtered through $0.45 \mu \mathrm{m}$ whatman filter paper and after suitable dilution, the amount of LS present in the film was determined spectrophotometrically at $276 \mathrm{~nm}$. (Nidhi et al. 2011).

(viii) Swelling index: Nidhi et al. (2011) states that, during the swelling studies the sample film was allowed to swell on the surface of an agar plate (prepared as described in the measurement of surface $\mathrm{pH}$ section), 50 $\mathrm{ml}$ of $\mathrm{pH} 6.8$ phosphate buffer mixed with $2 \%$ agar was poured into the petridish kept in an incubator maintained at $37^{\circ} \mathrm{C}$. After gelling, initial weight of the individual film was noted and then placed over the agar plate. An increase in the weight of the film was noted in $15 \mathrm{~min}$ intervals for $60 \mathrm{~min}$ and the weight was calculated. The swelling percentage was calculated by using the following formula:

$$
\text { Swelling Index }(\mathrm{SI})=\left\{\begin{array}{lc}
\frac{W_{t}-W_{0}}{W_{0}} & \begin{array}{cc}
100
\end{array}
\end{array}\right.
$$

Here, $W_{t}=$ mass of swollen films at time $\mathrm{t}$ and $W_{0}=$ mass of dry films at $\mathrm{t}=0$

(xi) In vitro release study: The dissolution study was carried out using a USP 23 Type-2 rotating paddle dissolution test apparatus (Electrolab, India; UDA-8D USP Standards). The dissolution medium used was 200 $\mathrm{mL}$ of simulated saliva solution $(\mathrm{pH} 6.8)$ at $37 \pm 2^{\circ} \mathrm{C}$, at $50 \mathrm{rpm}$. The film was fixed onto the specially designed stainless steel disk with the help of cyanoacrylate adhesive. The disk was put at the bottom of the dissolution vessel so that the film remained on the upper side of the disk. Samples (15mL) were withdrawn at pre-determined time intervals and replaced with an equal volume of dissolution medium. 
The samples were filtered through a $0.45-\mu \mathrm{m}$ whatman filter paper and appropriately diluted with simulated saliva solution ( $\mathrm{pH}$ 6.8) and assayed spectrophotometrically (Shimadzu Corporation, Japan) at $276 \mathrm{~nm}$. (Nidhi et al. 2011)

(x) Percentage moisture absorption (PMA): The percentage moisture absorption test was carried out to check the physical stability of the films at high humid conditions. Three films were weighed accurately then the films were placed in desiccator containing saturated solution of aluminium chloride, keeping the humidity inside the desiccator at $79.5 \%$. After 3 days the films were removed, weighed and percentage moisture absorption were calculated. Average percentage moisture absorption of three films were found. (Lohani et al., 2011)

$$
\text { PMA }=\frac{\text { Final weight }- \text { Initial weight }}{\text { Initial weight }} \times 10 \mathrm{C}
$$

(xii) Percentage moisture loss (PML): Percentage moisture loss was also carried to check the integrity of films at dry condition. Three films were weighed accurately and kept in desiccator's containing fused anhydrous calcium chloride. After 72 hours the films were removed, weighed. Average percentage moisture loss of three films was found out. (Lohani et al., 2011)

$$
\mathrm{PML}=\frac{\text { Final weight }- \text { Initial weight }}{\text { Initial weight }} \times 10 \mathrm{C}
$$

(xiii) Residence time (ex vivo mucoadhesion time): In order to determine the strength of mucoadhesion of LS films, USP dissolution appararus II was used. In the present study, sheep buccal mucosa was used as the mucosal membrane as it closely resembles the human buccal membrane in structure and permeability. The mucosal membrane was separated by removing the underlying fat and loose tissues. The membrane was washed with phosphate buffer $\mathrm{pH}$ 6.8. At first, the cutted sample of mucosa was fixed to beaker inner wall just above $2.5 \mathrm{~cm}$ above from the bottom of beaker. A sample of film was wetted in one side by Phosphate buffer pH 6.8 in order to make the film sticky and then attached to the buccal mucosal membrane by providing light force with finger tips for 30 seconds. Then, about $500 \mathrm{~mL}$ Phosphate buffer $\mathrm{pH} 6.8$ was added to the beaker in which the rotation of $50 \mathrm{rpm}$ and the temperature of $37 \pm 2^{\circ} \mathrm{c}$ were maintained. The time required to detach the film from the buccal mucosal membrane is the value of ex vivo mucoadhesion time (Prasanth et al. 2011).

\section{Results and Discussion}

Formulation of LS thin films: In the present study, OTF films of LS were prepared by different polymer combinations of HPMC K4M, SCMC, CP 934 P and PVP using the solvent casting method. A total of 5 formulations (F-1 to F-5) were prepared using plasticizer PG. Use of organic solvents was avoided to prevent any unwanted residual solvent complications. Use of water as a solvent was the reason for the long duration of drying time during the formulation step (about 20 hours).

Thickness, mass uniformity and folding endurance: Table 2 gives the average thickness values of films of all the formulation. The thickness was found to vary between $0.052 \pm 0.52$ to $0.219 \pm 0.65 \mathrm{~mm}$ from $\mathrm{F}$ 1 to F-5. A very low standard deviation value is indicating that the method used for the formulation of films is reproducible and give films of uniform thickness and hence dosage accuracy in each film can be ensured. The mass of the films varied between $28 \pm 0.08 \mathrm{mg}$ to $93 \pm 0.27 \mathrm{mg}$ for $\mathrm{F}-1$ to $\mathrm{F}-5$. It were noticed that the thickness as well as mass of the films showed almost reproducibility.

\begin{tabular}{|c|c|c|c|c|c|c|c|}
\hline $\begin{array}{c}\text { Formulation } \\
\text { Code }\end{array}$ & $\begin{array}{l}\text { Thickness } \\
\text { (mm) }\end{array}$ & $\begin{array}{c}\text { Mass } \\
\text { uniformity } \\
(\mathrm{mg})\end{array}$ & $\begin{array}{c}\text { Disintegration } \\
\text { time (min) }\end{array}$ & $\begin{array}{c}\text { Surface } \\
\mathrm{pH}\end{array}$ & $\begin{array}{l}\text { Folding } \\
\text { endurance }\end{array}$ & Density & $\begin{array}{c}\text { Content } \\
\text { uniformity } \\
(\%)\end{array}$ \\
\hline F-1 & $0.052 \pm 0.52$ & $28 \pm 0.08$ & $1.10 \pm 0.07$ & 7.0 & $>300$ & $0.012 \pm 0.04$ & 99.58 \\
\hline $\mathrm{F}-2$ & $0.060 \pm 0.18$ & $32 \pm 0.09$ & $5.00 \pm 0.15$ & 6.6 & $>300$ & $0.028 \pm 0.10$ & 107.34 \\
\hline F-3 & $0.146 \pm 0.43$ & $62 \pm 0.18$ & $5.00 \pm 0.11$ & 6.1 & $>300$ & $0.077 \pm 0.09$ & 87.90 \\
\hline F-4 & $0.179 \pm 0.53$ & $108 \pm 0.32$ & $3.50 \pm 0.13$ & 6.4 & $>300$ & $0.096 \pm 0.06$ & 99.82 \\
\hline F-5 & $0.219 \pm 0.65$ & $93 \pm 0.27$ & $5.00 \pm 0.04$ & 6.5 & $>300$ & $0.085 \pm 0.03$ & 85.90 \\
\hline
\end{tabular}

Table 2. Physicochemical characteristics of the LS thin films. 
The folding endurance was measured manually, by folding the film repeatedly at a point till they broke. The number of times of film could be folded at the same place without breaking gave the value of the folding endurance. Hence the breaking time was taken at the end. The folding endurance was found to be satisfactory i.e. greater than 300 (Table 2) for every formulations and don't show any visible cracks or folds.

Surface $\mathrm{pH}$ : The $\mathrm{pH}$ range of all the prepared formulations had showed the result that resembles the salivary fluid $\mathrm{pH}$ i.e. 6.1 to 7.0 (Table 2) and there was no significant difference of surface $\mathrm{pH}$ and hence no oral mucosal irritation will be result.

Density: Maximum density was found for F-1 $(0.085 \pm 0.03)$ in which the combination of polymer were HPMC K4M/SCMC. On the other hand, the lowest density was found for F-4 $(0.062 \pm 0.06)$ having combination of HPMC/CP 934 P/PVP. The density was increased in the following order: $\mathrm{F}-1<\mathrm{F}-2<\mathrm{F}-3<\mathrm{F}-5<\mathrm{F}-$ 4. (Table 2).

Drug content uniformity: The drug content of the prepared films is given in Table 2. The observed results of content uniformity indicate that the drug was uniformly dispersed throughout the film. The percentage drug content of all formulations was found to be between 85 to $115 \%$ which complies with limits established in the official compendia (The British Pharmacopoeia 2009). But the highest loading of drug $2.57 \pm 0.6 \mathrm{mg}$ reported with F-2 (107.34\%) and the lowest amount of drug loading found in F-5 i.e. $2.06 \pm 0.5 \mathrm{mg}(85.90 \%)$.

Disintegration time: The disintegration time for prepared formulation batches was found to be within the limits. As expected increase in the polymer concentration increases disintegration time while for a fixed polymer quantity higher plasticizer content resulted in faster disintegration of the films. F-1 showed fastest disintegration (approximately 1 minute) in which the polymer combination was HPMC- K4M/ SCMC (Table 2). Highest disintegration was found to be about 5 min both for F-2 \& F-3. The time of disintegration may be faster by the use of proper disintegrants in the formulation.

Swelling studies: The swelling indices of the films were high (up to $139.02 \%$ for F-5 at the end of $45 \mathrm{~min}$ ) and varied between the different compositions of polymers. Higher swelling indices may be due to the presence of water soluble polymers. The swelling behavior provides an indication of the relative moisture absorption capacities of polymers and whether the formulations maintain their integrity after absorption of moisture. Differences in swelling of the tested hydrophilic polymers could be explained by the difference in resistance of the matrix network structure (hydrogen bond) to the movement of water molecules. In addition, the presence of a water-soluble drug might have improved the surface wetting of the matrix. The swelling indices increased in the following order $\mathrm{F} 4<\mathrm{F} 1<\mathrm{F} 2<\mathrm{F} 3<\mathrm{F} 5$.

In vitro drug dissolution: In vitro drug release studies were performed for all the prepared formulation by using phosphate buffer $\mathrm{pH} 6.8$ as dissolution medium and measuring drug concentration UV spectrophotometrically at $\lambda_{\max } 276 \mathrm{~nm}$ that was determined previously. In order to ensure precise results, six samples of every formulation were taken for dissolution study. The studies were performed up to 150 minutes and triplicate data of each absorbance was noted. The results of in vitro release studies for F-1 to F-5 are given in Table 3. The graph was plotted by taking cumulative percentage release vs time (min). F-1 \& F-2 showed faster release as compared with others. The release of the LS from thin films are shown in Figure 2.

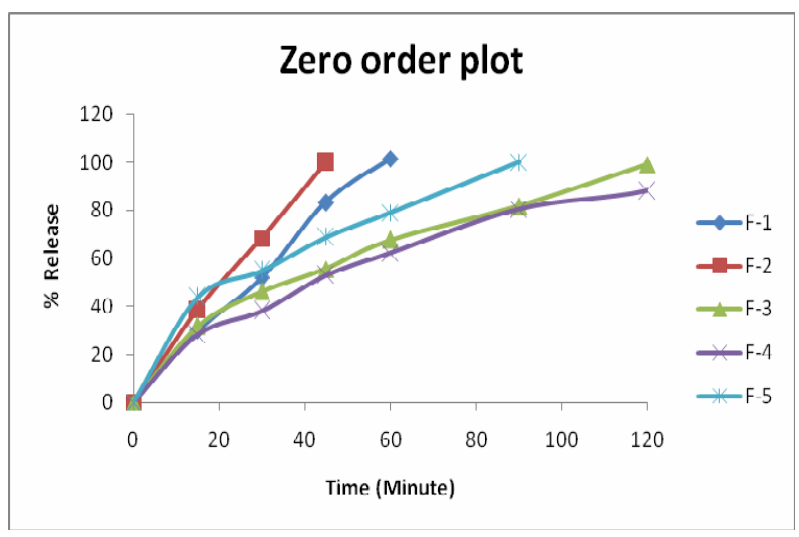

Figure 2. Zero order release profile.

From the Table 3, we see that, F-2 \& F-5 followed first zero order release kinetics having the polymeric combination namely HPMC K4M/ CP $934 \mathrm{P}$ \& HPMC K4M/ CP 934 P/SCMS successively. Whereas, F-1 \& F-4 have followed higuchi release having polymeric combination of HPMC K4M/SCMC \& HPMC K4M/CP 934 P/ PVP K30 respectively. Only F-3 have followed both zero order and hixon-crowell 
release which having the polymeric combination of HPMC K4M/ PVP K30.

Percent moisture absorption (PMA) and Percentage moisture loss (PML): Checking the physical stability of the film at high humid conditions and integrity of the film at dry conditions, the films were evaluated for PMA and PML respectively. The observed PMA for F-1 to F-5 were remain unchanged, whereas, PML value of F-1 to F-5 were in the order of $\mathrm{F} 5>\mathrm{F} 4>\mathrm{F} 1>\mathrm{F} 3>\mathrm{F} 2$. Relatively low standard deviation of result indicates the relative stability of the film in dry condition but revealed excellent stability against humid conditions.

Table 3. Linear regression equations $(Y=m x+c)$ \& Correlation co efficicent $\left(R^{2}\right)$ values of $L S$ thin films.

\begin{tabular}{ccccccccc}
\hline \multirow{2}{*}{ Code } & \multicolumn{2}{c}{ Zero Order } & \multicolumn{2}{c}{ First Order } & \multicolumn{2}{c}{ Higuchi } & \multicolumn{2}{c}{ Hixon-Crowell } \\
\cline { 2 - 9 } & $\mathrm{Y}=\mathrm{mx}+\mathrm{c}$ & $\mathrm{R}^{2}$ & $\mathrm{Y}=\mathrm{mx}+\mathrm{c}$ & $\mathrm{R}^{2}$ & $\mathrm{Y}=\mathrm{mx}+\mathrm{c}$ & $\mathrm{R}^{2}$ & \multicolumn{1}{c}{$\mathrm{Y}=\mathrm{mx}+\mathrm{c}$} & $\mathrm{R}^{2}$ \\
\hline F1 & $2.17 \mathrm{x}+6.45$ & 0.971 & $-0.017 \mathrm{x}+1.98$ & 0.955 & $14.46 \mathrm{x}-2.78$ & $\mathbf{0 . 9 7 9}$ & $-0.081 \mathrm{x}+4.88$ & 0.916 \\
F2 & $2.170 \mathrm{x}+6.41$ & 0.974 & $-0.019 \mathrm{x}+2.00$ & $\mathbf{0 . 9 9 5}$ & $14.49 \mathrm{x}-2.92$ & 0.985 & $-0.083 \mathrm{x}+4.89$ & 0.933 \\
F3 & $0.850 \mathrm{x}+5.43$ & $\mathbf{0 . 9 6 6}$ & $-0.009 \mathrm{x}+2.06$ & 0.948 & $9.656 \mathrm{x}-11.86$ & 0.932 & $-0.024 \mathrm{x}+4.74$ & $\mathbf{0 . 9 6 6}$ \\
F4 & $0.599 \mathrm{x}+18.6$ & 0.908 & $-0.007 \mathrm{x}+1.99$ & 0.969 & $8.245 \mathrm{x}-1.38$ & $\mathbf{0 . 9 9 3}$ & $-0.023 \mathrm{x}+4.66$ & 0.944 \\
F5 & $1.646 \mathrm{x}+6.48$ & 0.977 & $-0.015 \mathrm{x}+2.01$ & $\mathbf{0 . 9 9 6}$ & $12.85 \mathrm{x}-5.33$ & 0.971 & $-0.060 \mathrm{x}+4.90$ & 0.916 \\
\hline
\end{tabular}

Residence time (ex vivo mucoadhesion time): Among F-1 to F-5, mucoadhesive strength was found to be the best in F-5 (5.30min) where combination of polymers were HPMC K4M/CP 934P/SCMC and lowest residence time was found for F-1(1.45 $\mathrm{min})$ where polymeric combinations were HPMC K4M/ SCMC. Results indicated that the effect of carbopol 934P is more significant than SCMC and the higher concentration of carbopol 934P had a positive effect on in vivo mucoadhesive strength.

\section{Conclusion}

Novel mucoadhesive oral films of LS were developed to overcome the first-pass metabolism and subsequent low bioavailability of the LS. The in vitro and other studies have shown that this is a potential drug delivery system for LS with a considerably good physicochemical characteristics and release profile. Future studies are warranted to further scale up of formulations and to confirm these results elaborately in vivo as well as other parameter of the film such as dryness/tack test, tensile strength of the film, percent elongation, young's modulus etc. should be investigated. Another suitable plasticizer can also be investigated for future purpose.

\section{Acknowledgement}

The authors are thankful to Pharmaceutical Technology Laboratory, Department of Pharmacy,
State University of Bangladesh, Dhaka for excellent support and cooperation. Authors are also thankful to Beximco Pharmaceuticals Ltd \& Eskayef Bangladesh Ltd for gift samples.

\section{References}

Alpesh, R.P., Dharmendra, S.P. and Jignyasha, A.R. 2010. Fast dissolving films as a newer venture in fast dissolving dosage forms. Int. J. Drug Dev. Res. 2, 232246.

Bandari, M.R. and Gannu, R.R.Y. 2008. Oro dispersible tablets: An overview. Asian J Pharm. 2, 2-11.

Biradar S.S., Bhagavati S.T. and Kupassad I.J. 2006. Fast dissolving drug delivery systems: a brief overview. Int. J Pharmacol. 4.

Dixit, R.P. and Puthli, S.P. 2009. Oral strip technology: Overview and future potential. J Control Rel. 139, 94110.

Gavaskar, B., Kumar, S.V., Sharan, G. and Rao, Y.M. 2010, Overview of fast dissolving films. Int J Pharm Sci. 2, 2933.

Lohani, A., Prasad, N. and Arya, R.K.K. 2011. Formulation \& Characterization of mucoadhesive buccal films of Ranitidine Hydrochloride. Int. J. Pharm. Sci. Res. 2, 2457-2462.

Nidhi, P.S., Vaishali, A.K., Anwar, S.D. and Minal, N. 2011. Development of fast dissolving oral thin films of ambroxol hydrochloride: effect of formulation variables. J. Adv. Pharm. Res. 2, 102-109.

Shinde, A.J. and Garala, K.C. 2008. Development and Characterization of transdermal therapeutics system of tramadol hydrochloride. Asian J Pharm. 2, 265-269. 
Patel, R.S. and Poddar, S.S. 2009. Development and characterization of mucoadhesive buccal patches of salbutamol sulphate. Current Drug Delivery. 6, 140-144.

Prasanth, V.V. and Mathew, S.T. 2011. Development and Characterization of mucoadhesive patches of salbutamol sulfate for unidirectional buccal drug delivery. Acta Pharm. 61, 157-170.
Schreck, D.M. and Babin, S. 2005. Comparison of racemic albuterol and levalbuterol in the treatment of acute asthma in the ED. Am. J. Emerg Med. 23, 842-847.

Khairwa, A. and Jat, K.R. 2013. Levalbuterol versus albuterol for acute asthma: a systematic review and meta-analysis. Pulm Pharmacol Ther. 26, 239-248. 